\title{
PDZ-binding kinase/T-LAK cell-originated protein kinase is a target of the fucoidan from brown alga Fucus evanescens in the prevention of EGF-induced neoplastic cell transformation and colon cancer growth
}

\author{
Olesia S. Vishchuk ${ }^{1,2, *}$, Huimin Sun ${ }^{3, *}$, Zhe Wang ${ }^{4}$, Svetlana P. Ermakova ${ }^{2}$, JuanJuan \\ Xiao $^{1}$, Tao Lu ${ }^{1}$, PeiPei Xue ${ }^{1}$, Tatyana N. Zvyagintseva ${ }^{2}$, Hua Xiong ${ }^{1}$, Chen Shao ${ }^{3,5}$, \\ Wei Yan ${ }^{4}$, Qiuhong Duan ${ }^{1}$, Feng Zhu ${ }^{1}$ \\ ${ }^{1}$ Department of Biochemistry and Molecular Biology, School of Basic Medicine, Huazhong University of Science and Technology, \\ Wuhan, Hubei 430030, PR China \\ ${ }^{2}$ G.B. Elyakov Pacific Institute of Bioorganic Chemistry, Far Eastern Branch of Russian Academy of Sciences, Laboratory of \\ Enzyme Chemistry, 690022 Vladivostok, Russian Federation \\ ${ }^{3}$ Department of Urology, Xijing Hospital, The Fourth Military Medical University, Xi'an, Shaanxi 710032, PR China \\ ${ }^{4}$ Department of Pathology, Xijing Hospital, The Fourth Military Medical University, Xi'an, Shaanxi 710032, PR China \\ ${ }^{5}$ State Key Laboratory of Cancer Biology \& Xijing Hospital of Digestive Diseases, The Fourth Military Medical University, Xi'an, \\ Shaanxi 710032, PR China \\ * These authors have contributed equally to this work \\ Correspondence to: Wei Yan, e-mail: yanwei@fmmu.edu.cn \\ Qiuhong Duan, e-mail: duanqhwz@hust.edu.cn \\ Feng Zhu, e-mail: fengzhu@hust.edu.cn \\ Keywords: fucoidan, Fucus evanescens, TOPK, cell transformation, colon carcinoma \\ Received: November 01, 2015 \\ Accepted: January 29, 2016 \\ Published: February 25, 2016
}

\section{ABSTRACT}

The fucoidan with high anticancer activity was isolated from brown alga Fucus evanescens. The compound effectively prevented EGF-induced neoplastic cell transformation through inhibition of TOPK/ERK1/2/MSK 1 signaling axis. In vitro studies showed that the fucoidan attenuated mitogen-activated protein kinases downstream signaling in a colon cancer cells with different expression level of TOPK, resulting in growth inhibition. The fucoidan exerts its effects by directly interacting with TOPK kinase in vitro and ex vivo and inhibits its kinase activity. In xenograft animal model, oral administration of the fucoidan suppressed HCT 116 colon tumor growth. The phosphorylation of TOPK downstream signaling molecules in tumor tissues was also inhibited by the fucoidan. Taken together, our findings support the cancer preventive efficacy of the fucoidan through its targeting of TOPK for the prevention of neoplastic cell transformation and progression of colon carcinomas in vitro and ex vivo.

\section{INTRODUCTION}

Cancer is considered to be a leading cause of death worldwide despite the intensive efforts and substantial advances that have occurred through focusing on improving treatments. Recently it was indicated that onethird of all cancer deaths are preventable and that diet is closely linked to cancer prevention. Chemoprevention may be defined as the use of non-toxic substances, including many food factors and natural compounds to interfere with the process of cancer development or carcinogenesis before invasion and metastasis can occur. On the basis of this idea, and numerous epidemiological findings, attention has centred on dietary natural compounds as an effective intervention in cancer development [1].

A great deal of interest has been developed in the nutraceutical and pharmaceutical industries to isolate natural biological active compounds from marine resources. Among marine organisms, brown algae belonging to Saccharina, Fucus, Alaria, Sargassum, Undaria, Pelvetia genera have traditionally formed part of the oriental diet, especially in Asian-pacific region, 
while the purified gelling and thickening ingredients are predominant as food products of algal origin in European countries and USA. Nowadays, algae have been marketed worldwide as constituents of dietary supplements due to their antimutagenic, anticoagulant, and antitumor properties as well as the high content of so-called dietary fiber [2]. Brown algae are known to produce a range of active components including unique secondary metabolites such as phlorotannins and polysaccharides, namely alginic acids, laminarans, and sulfated polysaccharides (fucoidans). The fucoidans are shown to be a topic of numerous studies as nontoxic compounds, possessing wide spectrum of biological activities [3, 4]. The fucoidans from different species of brown algae have been found to inhibit carcinogenesis in variety of cancer cells, including gastric adenocarcinoma [5], prostate cancer [6], melanoma [7], hepatocellular carcinoma [8], breast cancer [9], and colon cancer cells [10].

The key molecular mechanism of anticancer effect of the fucoidans is the induction of apotosis through caspase-dependent and caspase-independent pathways [11-14]. Moreover the fucoidans were shown to suppress tumor growth by inhibiting tumor-induced angiogenesis and metastasis [15]. The mechanism by which the fucoidans inhibited these processes has not been clearly elucidated. Probably, the fucoidans are responsible for the reduction of activities of Matrix Metalloproteinases (MMPs) and the decrease of Vascular Endothelial Growth Factor (VEGF) expression with subsequent inhibition of invasion and suppression of tubules formation in tumor cells [16-18].

While the development of research efforts involving structure of the fucoidans and their biological activities are advancing, the understanding of molecular mechanisms of their action is still incomplete. Moreover, a direct molecular target of the fucoidan from brown alga Fucus evanescens has not been identified in vitro or ex vivo.

The mitogen-activated protein kinase kinase (MAPKK) signaling pathway is a major component of the RAS/RAF/MEK/ERK signaling axis which is activated by a multitude of extracellular stimuli, including a variety of tumor promoters; and they participate in the regulation of a host of cellular functions such as transformation, proliferation and growth, cell movement, differentiation, and death [19].

The Lymphokine-activated killer T-cell-originated protein kinase (TOPK) is a serine-threonine kinase, a member of MAPKK family. TOPK was confirmed to highly express in many cancers such as lymphoma, leukemia, melanoma, colorectal, breast, lung cancer, and cholangiocarcinoma [20-22]. In addition, TOPK may contribute to oncogenic cellular functions including tumor development, cancer growth, and antiapoptotic effects [2325]. On the basis of the above the TOPK kinase is certain to be a potential target for development of anticancer agents.
The aim of the present study was to elucidate molecular mechanism of chemopreventive effect of the fucoidan from brown alga Fucus evanescens and identify its direct molecular target.

\section{RESULTS}

\section{The fucoidan inhibits EGF-induced neoplastic transformation of JB6 Cl41 cells through TOPK/ ERK1/2/MSK 1 pathway}

The carcinogenesis is multistage process, including initiation, promotion, and progression [26]. One of the perspective approaches for cancer therapy is search and development of nontoxic compounds, which are effective in preventing of cancer initiation.

The promotion-sensitive mouse epidermal cells JB6 Cl41 are known to respond irreversibly to tumor promoters such as epidermal growth factor (EGF) with induction of anchorage-independent growth in soft agar $[27,28]$. That is why this well-established culture system was used to identify effect of the fucoidan from brown alga Fucus evanescens (FeF) on EGF-induced neoplastic cell transformation.

FeF (Figure 1A) was shown to inhibit EGF-induced neoplastic transformation of JB6 Cl41 cells in dosedependent manner. FeF at concentrations 100, 200, 400 $\mu \mathrm{g} / \mathrm{mL}$ decreased the number of transformed cells on $30,35,60 \%$, respectively (Figure 1B). It should be noted that the chemopreventive effect of FeF was not due to its cytotoxicity, because it did not possess cytotoxicity at concentration range up to $1 \mathrm{mg} / \mathrm{mL}$ even in 3 days of treatment (Figure 1C).

To elucidate molecular mechanism of chemopreventive effect of FeF we tested MEK1/2/TOPK/ ERK1/2/MSK 1 pathway, which is link extracellular signals to the machinery that controls fundamental cellular processes such as growth, proliferation, differentiation, migration and apoptosis [29, 30]. Therefore, herein we investigated the effect of $\mathrm{FeF}$ on the phosphorylation of MEK1/2, TOPK, ERK1/2, MSK 1 kinases in JB6 C141 cells. The FeF was found to inhibit EGF-induced phosphorylation of TOPK, ERK1/2, and MSK 1, but not MEK1/2 kinase. FeF did not influence expression of MEK1/2, TOPK, ERK1/2, and MSK 1 total protein level (Figure 1D).

\section{The fucoidan inhibits colony formation of colon cancer cells}

Previous studies suggested that TOPK is highly activated in human colon cancer [20]. Therefore, in our study to determine the effect of FeF on colony formation we used colon cancer cell lines HCT 116, HT-29, and WiDr with high, middle, and low expression level of TOPK, respectively (Figure 2A). Cells were maintained 
with different concentrations of FeF $(0-400 \mu \mathrm{g} / \mathrm{mL})$ and colony numbers were counted after culturing for 14 days. The results showed that the fucoidan at 100, 200, and $400 \mu \mathrm{g} / \mathrm{mL}$ inhibited colony formation of HCT 116 on 35,57 , and $58 \%$; HT-29 cells on 21,31 , and $36 \%$ and WiDr on 6,14 , and $16 \%$, respectively, compared with nontreated cells (Figure 2B-2D). Overall, our results suggest that inhibitory effect of FeF on colony formation was significant in HCT 116 cells with high expression level of TOPK.

In addition, to examine the mechanism explaining the chemopreventive effect of FeF on colony formation of colon cancer cells, Western Blotting was used to evaluate the effect of FeF on phosphorylation of MEK1/2, TOPK and its downstream targets, including the phosphorylation of histone H2AX, ERK1/2, and MSK 1 proteins in HCT 116 cells, which were relatively more sensitive to FeF. As expected, phosphorylation of TOPK and down-regulated kinases was inhibited dose-dependently, but not MEK1/2

A

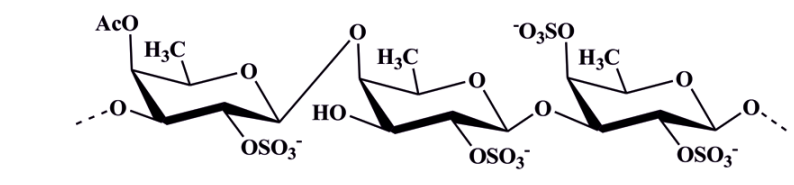

B
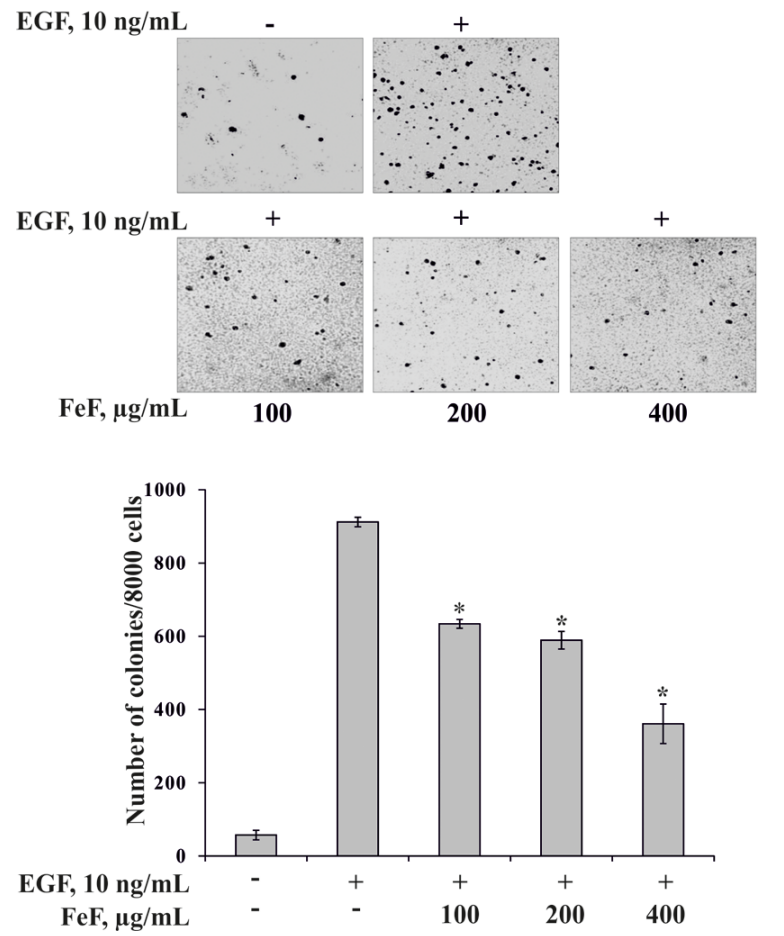

(Figure 3). It should be noted that FeF did not influence expression of MEK1/2, TOPK, ERK1/2, and MSK 1 total protein level.

\section{The fucoidan inhibits TOPK kinase activity in vitro}

We next investigated whether the fucoidan might influence kinase activity of TOPK for the inhibition of cells transformation. Data from in vitro kinase assays indicated that FeF decreased TOPK kinase activity (Figure 4A). FeF at concentrations of 200 or $400 \mu \mathrm{g} / \mathrm{mL}$ inhibited TOPK kinase activity on $28 \%$ or $64 \%$, respectively.

\section{The fucoidan specifically binds with TOPK in vitro and ex vivo}

The results above showed that the inhibition of EGF-induced neoplastic cell transformation and colony

C

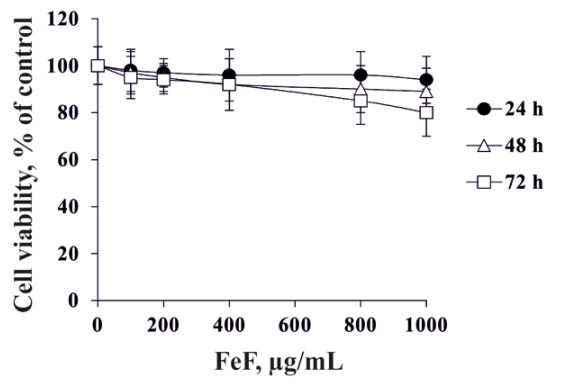

D

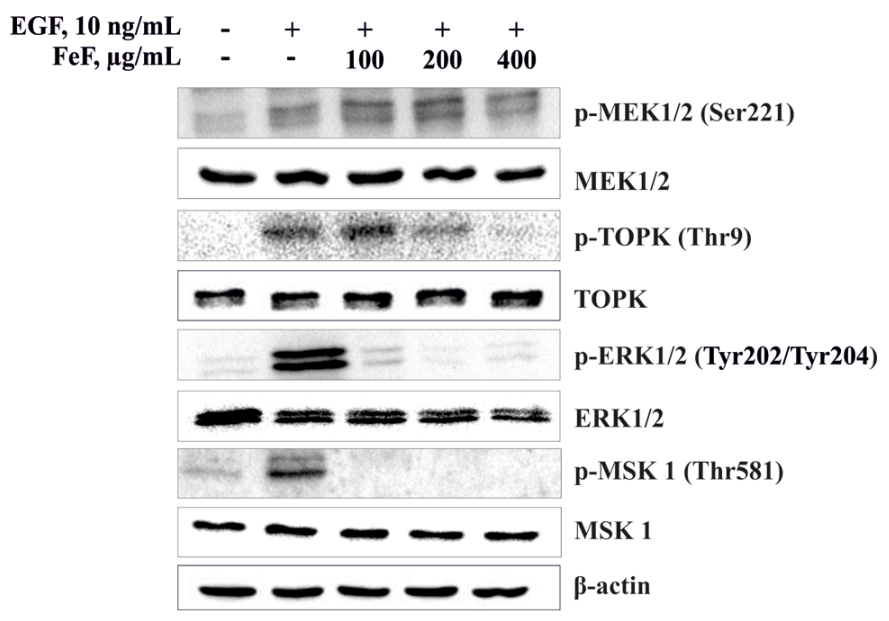

Figure 1: The effect of FeF on EGF-induced neoplastic transformation and molecular mechanism in JB6 Cl41 cells. A. The chemical structure of FeF. B. FeF inhibits EGF-induced anchorage-independent growth of mouse epidermal JB6 C141 cells. Data are shown as means \pm standard deviation of values from three independent experiments. The asterisk $(*)$ indicates a significant decrease in colony formation in cells treated with FeF compared with the non-treated cells $(* p<0.05)$. C. Cytotoxic effects of FeF on JB6 Cl41 cells. An MTS assay was used after treatment of cells with FeF for 24, 48, and $72 \mathrm{~h}$, respectively. All the experiments were performed in triplicate, and the mean absorbance values were calculated. D. FeF inhibits TOPK/ERK/MSK 1 signal transduction in JB6 C141 cells as determined by Western Blotting with specific antibodies. 
formation of colon cancer cells by $\mathrm{FeF}$ involves the suppression of TOPK kinase activity and, subsequently, TOPK downstream signaling pathways. To determine whether FeF exerts its effects by directly interacting with TOPK, we performed pull-down assay using insoluble fucoidan (IFeF) and TOPK-Ni-NTA-agarose beads. We found that TOPK associated with IFeF in vitro (Figure 4B, lane 3 ) and ex vivo (Figure $4 \mathrm{C}$, lane 3 ), but not with $\mathrm{BaSO}_{4}$ beads alone (Figure 4B, 4C, lane 2). Moreover FeF was proved to bind with TOPK-Ni-NTA-agarose beads (Figure 4D, lane 5), but not to Ni-NTA-agarose alone by colorimetric method with toluidine blue (Figure 4D, lane 4).

\section{The fucoidan inhibits growth of colon cancer cells in a xenograft model}

In order to determine the antitumor activity of $\mathrm{FeF}$ ex vivo, HCT 116 colon cancer cells were innoculated into the right flank of individual athymic nude mice. Then mice were administered vehicle or FeF (1, 10 or $50 \mathrm{mg}$ / $\mathrm{kg}$ of body weight) by oral injection, 3 times a week for 20 days. The treatment of mice with 1,10 , and $50 \mathrm{mg} /$ $\mathrm{kg}$ of body weight of FeF was found to inhibit HCT 116 tumor growth by 2,37 , and $72 \%$, respectively, compared with vehicle-treated group (Figure 5A, 5B). It was also shown that mice treated with FeF did not lose body weight compared with vehicle-treated group, which indicated that the dose of FeF used for the experiment had no toxicity to the mice (Figure 5C).

To check whether the antitumor effect of FeF was associated with its inhibition of TOPK activity, tumor tissues from each group were prepared after 20 days of treatment and analyzed for phosphorylation of TOPK downstream targets (p-ERK1/2 (Tyr202/Tyr204) and p-histone H3 (Ser10)) by H\&E and immunohistochemistry analyses. The results revealed that expression of $\mathrm{p}-\mathrm{ERK} 1 / 2$ and p-histone $\mathrm{H} 3$ was decreased after treatment with FeF at either 10 or $50 \mathrm{mg} / \mathrm{kg}$ of body weight compared with the control group (Figure 5D). Our data confirm that the fucoidan from brown alga $F$. evanescens suppresses tumor growth by inhibiting TOPK activity ex vivo.
A

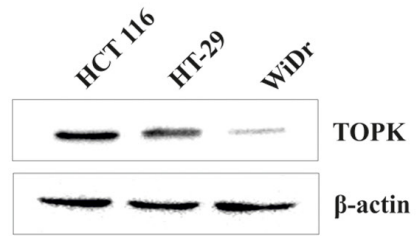

B

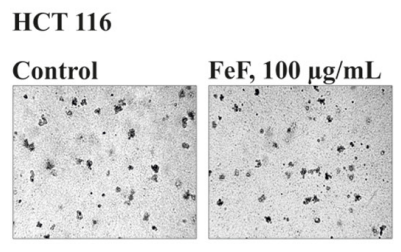

FeF, $200 \mu \mathrm{g} / \mathrm{mL} \quad$ FeF, $400 \mu \mathrm{g} / \mathrm{mL}$
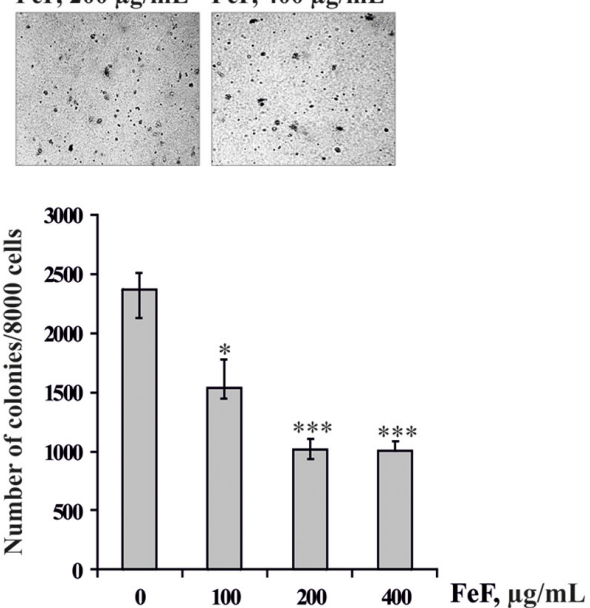

D
HT-29

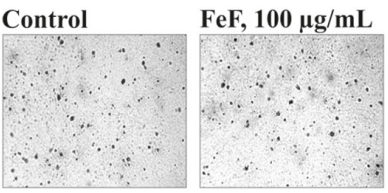

FeF, $200 \mu \mathrm{g} / \mathrm{mL} \quad \mathrm{FeF}, 400 \mu \mathrm{g} / \mathrm{mL}$
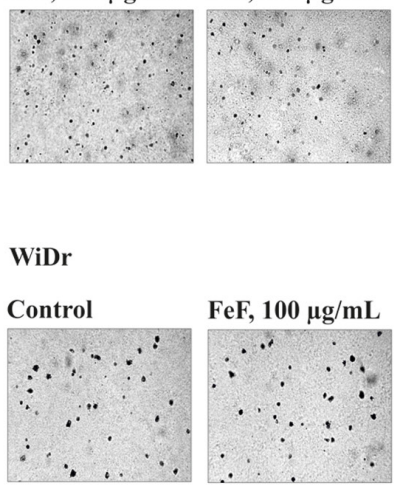

FeF, $200 \mu \mathrm{g} / \mathrm{m} \quad \mathrm{FeF}, 400 \mu \mathrm{g} / \mathrm{mL}$
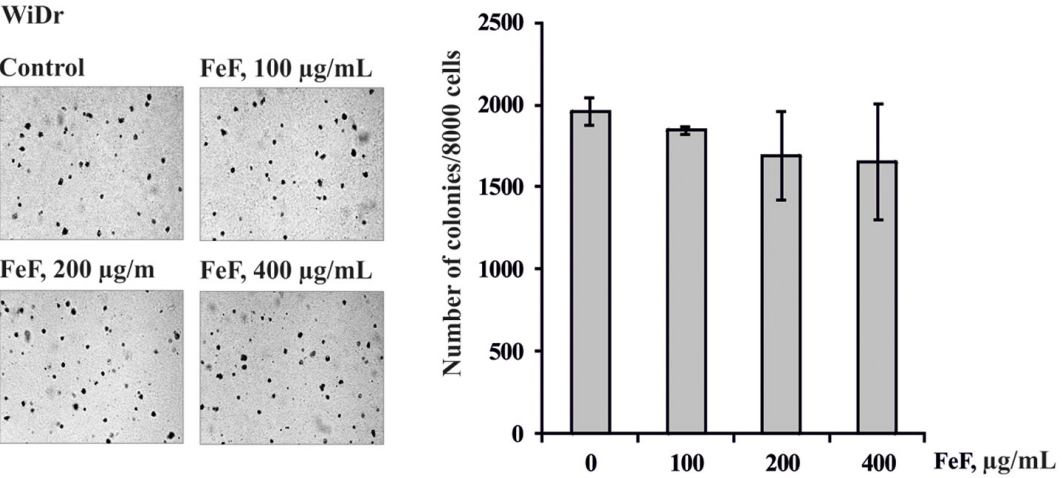

Figure 2: The effects of FeF on colony formation of colon carcinoma cells. A. Expression of TOPK in colon carcinoma cell lines HCT 116, HT-29 or WiDr. B, C, D. The effect of FeF on colony formation in HCT 116, HT-29 or WiDr cells with different level of TOPK expression. Data are shown as means \pm standard deviation of values from three independent experiments. The asterisk $(*)$ indicates a significant decrease in colony formation in cells treated with FeF compared with the non-treated cells $\left({ }^{*} p<0.05, * * * p<0.001\right)$. 


\section{DISCUSSION}

The fucoidans, sulfated polysaccharides, are constituents of brown algae and some marine invertebrates (such as sea urchins and sea cucumbers) [31,32]. The fucoidans isolated from different species of brown algae have extremely diverse chemical structure. And biological activity of the fucoidans was proved to depend on their structural characteristics $[33,34]$. The fucoidan from brown alga Fucus evanescens (FeF), studied in this work consists of alternating $(1 \rightarrow 3)$ - and $(1 \rightarrow 4)$-linked $\alpha$-Lfucopyranose residues, sulfated and partially acetylated at $\mathrm{C} 2$ and/or $\mathrm{C} 4$ positions $[35,36]$. For the past decade the fucoidans isolated from different species of brown algae have been extensively studied due to their varied biological activities including anticoagulant, antivirus, antitumor, immunomodulatory, anti-inflammatory, antioxidant, and anticomplementary activities [3, 4]. In vitro, several mechanisms have been postulated to underlie the anticancer activity of the fucoidans including induction of apoptosis in different types of cancer cells and prevention of angiogenesis and invasion in fibrosarcoma cells [9-18]. However the molecular mechanism of cancer preventive effect of the fucoidans and, moreover, their direct molecular targets has not been identified in vitro or ex vivo.

The MAP kinases comprise a family of proteins that mediate a succession of discrete signaling cascades. These signaling cascades are activated by a multitude of extracellular stimuli, including a variety of tumor promoters; and they participate in the regulation of a host of cellular functions such as proliferation, cell movement, differentiation, senescence, and death [19]. T-LAK celloriginated protein kinase (TOPK) is a novel serinethreonine kinase that is a member of MAPKK family and is involved in many cellular functions, including tumor development, cell growth, apoptosis, and inflammation $[20,37-39]$. Thus, TOPK is found to be a potential target for development of anticancer agents. Our results showed that $\mathrm{FeF}$ at nontoxic doses effectively suppressed EGF-induced transformation of JB6 C141 cells that was accompanied by decreased phosphorylation of TOPK

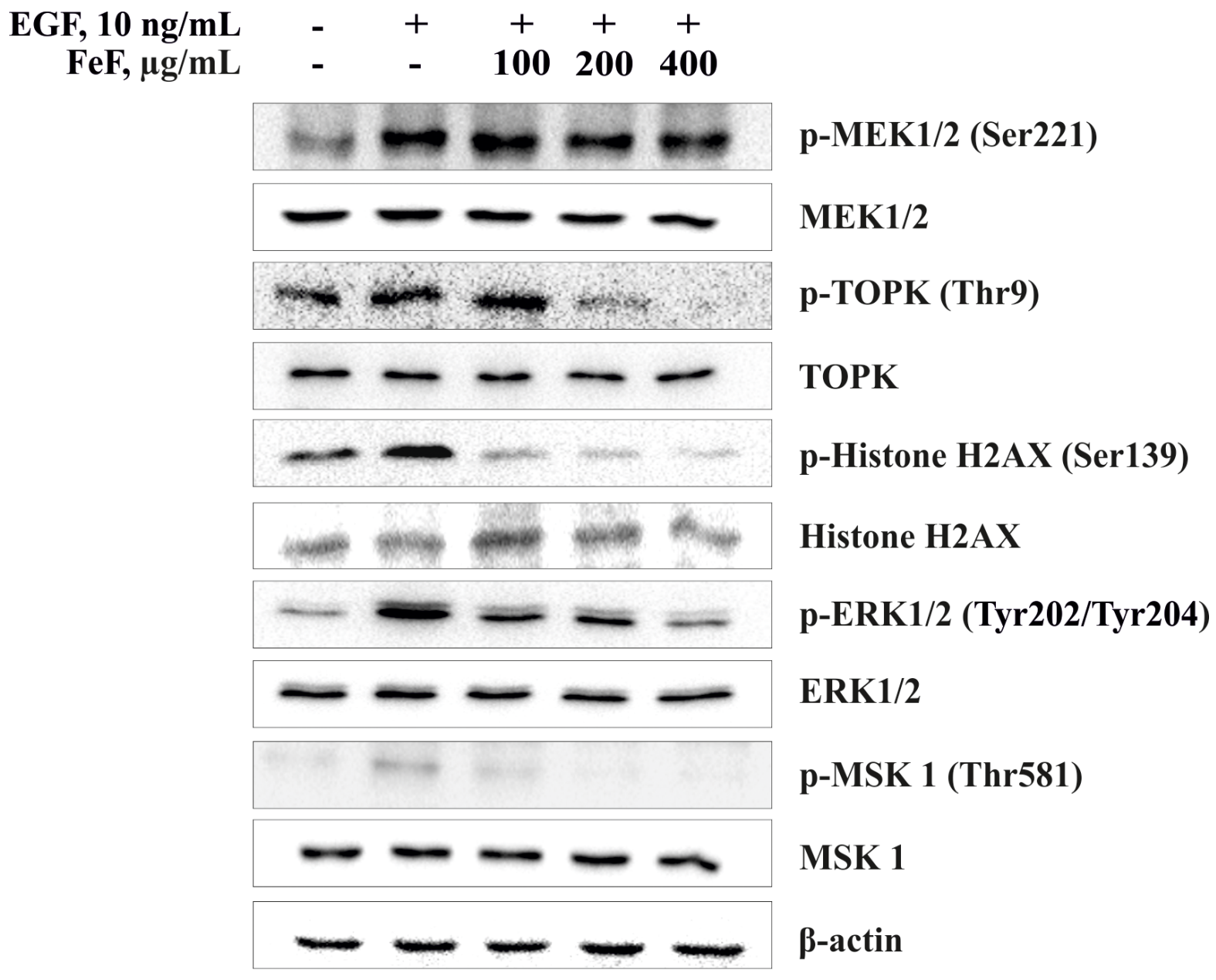

Figure 3: The effect of FeF on EGF-induced phosphorylation of MEK1/2/TOPK/ERK1/2/MSK 1 signaling pathway in HCT 116 cells. FeF inhibited EGF-induced phosphorylation of TOPK, H2AX, ERK1/2 or MSK 1, but not MEK1/2 in HCT 116 cells as determined by Western Blotting with specific antibodies. 
(Thr9), ERK1/2 (Tyr202/204) and MSK 1 (Thr581), but not MEK1/2 (Ser221), which suggested that FeF attenuated EGF-induced cell transformation by inhibiting of TOPK activity. TOPK/ERK1/2/ MSK 1 pathway is likely to play an important role in the cancer preventive activity of FeF. To the best of our (admittedly limited) knowledge, the effect of algal fucoidans on neoplastic cell transformation was not investigated in detail with the notable exception of our works [40, 41], in which the fucoidans were effective in inhibiting EGF-induced cell transformation of JB6 Cl41 cells. The inhibition was found to be associated with the inhibitory effects of polysaccharides on AP-1 activity. However the antitumor activity is known to depend on the structure of the fucoidans, therefore we can affirm that FeF has a unique molecular mechanism of cancer preventive action, which is necessary to be elucidated.

Because TOPK is highly activated in colon cancer cells we checked the idea whether FeF could suppress colony formation of colon cancer cells. In our study we compare the effect of FeF on anchorage-independent growth of colon cancer cells with different level of TOPK expression. It was shown that the fucoidan effectively suppressed colony formation of colon cancer cells HCT 116 with high expression level of TOPK and had less effect on HT-29 and WiDr cells with middle and low TOPK expression level, respectively. The fucoidan was confirmed to inhibit activity of TOPK, The fucoidan was

A

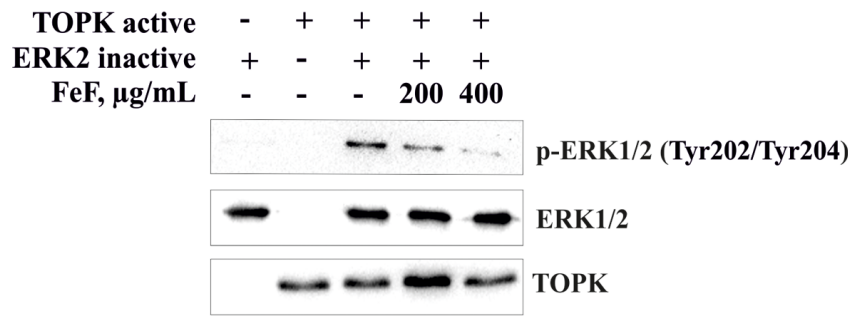

B

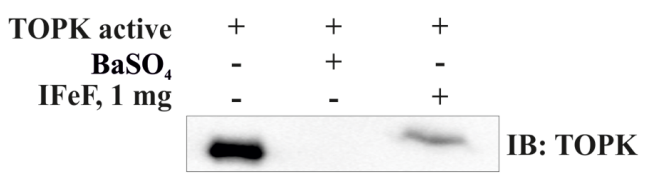

C

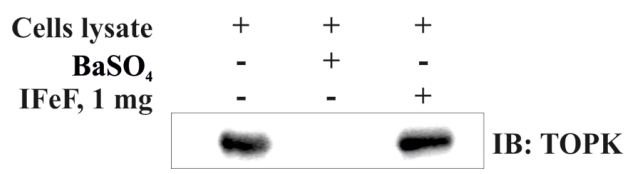

confirmed to inhibit phosphorylation of TOPK (Thr 9), and suggesting fucoidan may inhibit upstream kinase of TOPK, such as Erk-2 (Figure 1D and Figure 3). Further study is needed to explore the effect of fucoidan on feedback loop between TOPK and Erk2 or other upstream kinases of TOPK.

We first determined that FeF could potently suppress TOPK kinase activity in vitro. We further conducted in vitro and ex vivo pull-down assays and confirmed the direct binding between FeF and the TOPK kinase. Recently it was shown that TOPK inhibitor HI-TOPK-032 strongly suppressed TOPK kinase activity and inhibited anchorage-dependent and -independent colon cancer cell growth by reducing ERK-RSK phosphorylation as well as increasing colon cancer cell apoptosis through regulation of the abundance of p53, cleaved caspase-7, and cleaved PARP [42]. However in our study the inhibitory effect of natural compound from brown alga on TOPK was demonstrated for the first time.

Importantly, it was shown that FeF inhibited growth of HCT 116 colon tumor in xenograft animal model. The chemopreventive effect of FeF seemed to be associated with inhibition of the phosphorylation of ERK1/2 and histone $\mathrm{H} 3$, direct downstream signaling targets of TOPK. The obtained data strongly indicate that the chemopreventive effect of the fucoidan from brown alga F. evanescens in vitro corresponds closely with the results ex vivo.

D
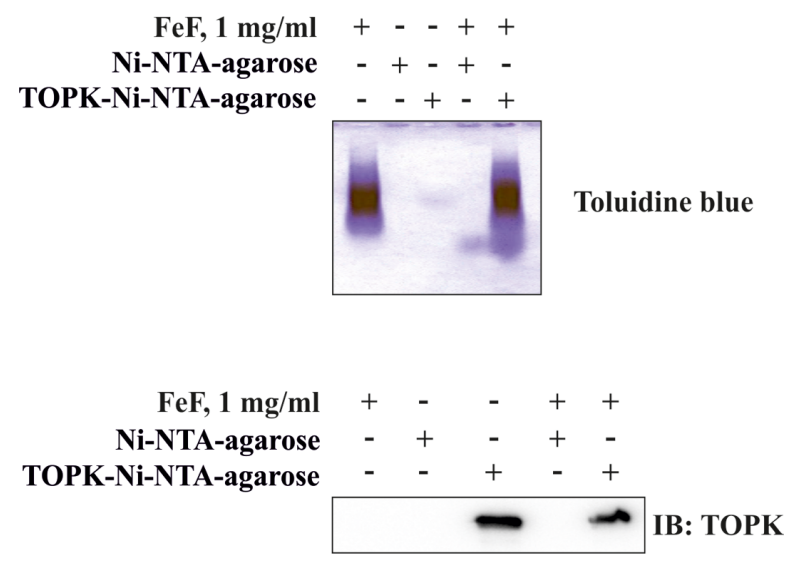

Figure 4: The effect of FeF on TOPK kinase activity in vitro and direct binding with TOPK in vitro and ex vivo. A. FeF inhibited TOPK kinase activity as determined by Western Blotting. Insoluble fucoidan (IFeF) and TOPK-Ni-NTA-agarose beads were used for binding and pull-down assays as described in Materials and Methods section. B, C. Lane 1 is input control (TOPK protein and HCT 116 cell lysate); lane 2 is the negative control, indicating no binding between TOPK and $\mathrm{BaSO}_{4}$, and lane 3 shows that TOPK binds with IFeF pellet. D. Lane 1 is input control (FeF); lane 2-4 is the negative control, indicating no binding between FeF and Ni-NTA-agarose beads, and lane 5 indicates that FeF binds with TOPK-Ni-NTA-agarose beads. 
In summary, we provided evidence showing that natural sulfated polysaccharide from brown alga Fucus evanescens effectively suppresses EGF-induced transformation of mouse epidermal cells JB6 Cl41 and colony formation of colon cancer cells through TOPK/ ERK1/2/ MSK 1 signal pathway by inhibiting TOPK kinase activity in vitro and ex vivo. Overall, our findings support the cancer preventive efficacy of the fucoidan through its targeting of TOPK for the treatment of colon carcinomas.

\section{MATERIALS AND METHODS}

\section{Reagents and antibodies}

The fucoidan FeF was isolated and purified from brown alga Fucus evanescens by the modified method [43]. Its structural characteristics were determined as previously described $[35,36]$.

MTS [3-(4,5-dimethylthiazol-2-yl)-5-(3carboxymethoxyphenyl)-2-(4-sulfophenyl)-2H-tetrazolium, inner salt] assay kit was purchased from "Promega" (Madison, WI, USA).
Antibodies against p-MEK1/2 (Ser221), p-ERK1/2 (Tyr202/Tyr204), p-TOPK (Thr9), p-histone H2AX (Ser139), p-histone H3 (Ser10), p-MSK 1 (Thr581), MEK1/2, ERK1/2, TOPK, histone H2AX, MSK 1 were obtained from "Cell Signaling Technology" (Massachusetts, USA), $\beta$-actin and horseradish peroxidase (HRP) conjugated secondary antibody from rabbit and mouse were purchased from "Santa Cruz" (Dallas, Texas, USA) and "Protein Tech Group" (Chicago, IL, USA), respectively.

The chemiluminescence's detection kit ECL Plus was from "GE Healthcare" (Pittsburgh, PA, USA).

The Basal Medium Eagle (BME), Dulbecco's Modified Eagle medium (DMEM), Minimum Essential medium (MEM), McCoy's 5A Modified medium (McCoy's 5A), Roswell Park Memorial Institute medium (RPMI 1640), phosphate buffered saline (PBS), L-glutamine, gentamicin solution, trypsin, fetal bovine serum (FBS), sodium hydrocarbonate $\left(\mathrm{NaHCO}_{3}\right)$, and agar were purchased from "Sigma" (St. Louis MO, USA) and "Gibco" (Grand Island, NY, USA). All other common chemicals, solvents and reagents were of highest grade available from various commercial sources.
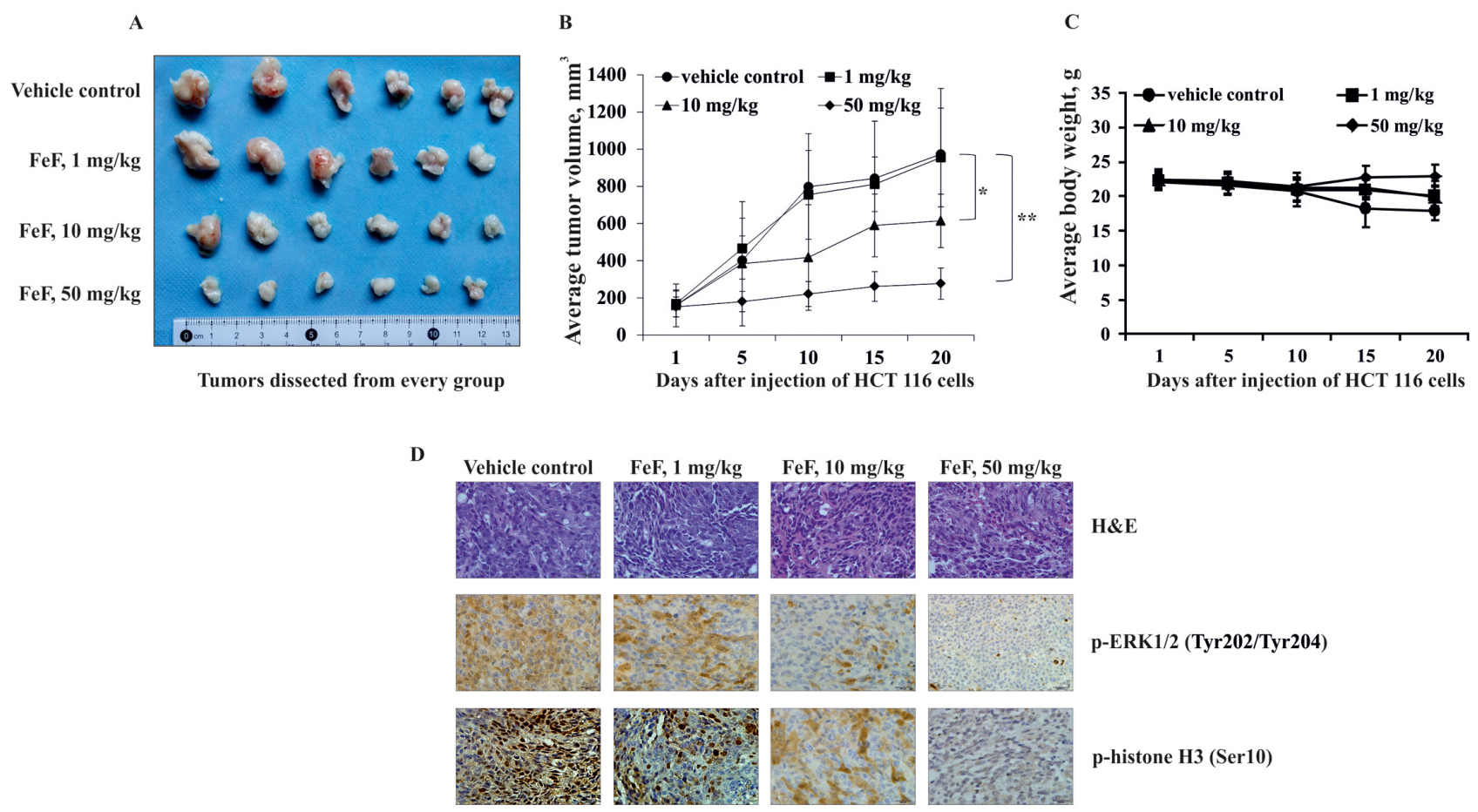

$H \& E$

p-ERK1/2 (Tyr202/Tyr204)

p-histone H3 (Ser10)

\begin{abstract}
Figure 5: The effect of FeF on tumor growth and phosphorylation of TOPK downstream signaling targets in HCT 116 xenograft mouse model. A. Tumors dissected from every group. B. FeF significantly inhibited colon tumor growth. The average tumor volume of vehicle-treated control mice and FeF-treated mice plotted over 20 days after HCT 116 cells injection. Data are shown as means \pm standard deviation of measurements. The asterisk $(*)$ indicates a significant inhibition of tumor growth by FeF $(* p<0.05, * * p<0.01)$. C. FeF does not affect mice body weight. Body weight from treated or untreated groups of mice was measured every other day. D. H\&E staining and the immunohistochemical analysis of tumor tissues. Treated or untreated groups of mice were euthanized and tumors extracted. Colon cancer tissue slides were prepared with paraffin sections after fixation with formalin and then stained with H\&E or p-ERK1/2 and p-histone H3. The magnification of representative photos for H\&E and the immunohistochemical staining is $\times 40$.
\end{abstract}




\section{Cell lines and culture conditions}

Mouse epidermal JB6 Cl41 cells (ATCC \# CRL2010) and human colon cancer cells HCT 116 (ATCC \# CCL-247TM), HT-29 (ATCC \# HTB-38), WiDr (ATCC \# CCL-218 ${ }^{\mathrm{TM}}$ ) were obtained from the American Type Culture Collection (Manassas, VA, USA).

Mouse epidermal JB6 Cl41, human colon cancer HCT 116, HT-29, and WiDr cells were cultured in MEM $/ 5 \%$ FBS, DMEM/10\% FBS, McCoy's 5 A/10\% FBS, and RPMI-1640/10\% FBS media, respectively. The cell cultures were maintained at $37^{\circ} \mathrm{C}$ in humidified atmosphere containing $5 \% \mathrm{CO}_{2}$.

\section{MTS assay}

To estimate cell viability, JB6 Cl41, HCT 116, HT-29 or WiDr cells $\left(8 \times 10^{3} /\right.$ well $)$ were seeded in 96 well plates for $24 \mathrm{~h}$ at $37^{\circ} \mathrm{C}$ in $5 \% \mathrm{CO}_{2}$ incubator. The attached cells were fed with fresh medium containing various concentrations of the fucoidan from brown alga F. evanescens $(\mathrm{FeF})(0-1000 \mu \mathrm{g} / \mathrm{mL})$ for additional 24,48 , $72 \mathrm{~h}$. After culturing for various times, the cytotoxicity of FeF was measured using an MTS assay kit according to the manufacturer's instructions. All the experiments were performed in triplicate, and the mean absorbance values were calculated. The results are expressed as the percentage of inhibition that produced a reduction in absorbance by the fucoidan's treatment compared to the non-treated cells (control).

\section{Anchorage-independent growth assay (soft agar assay)}

JB6 Cl41 cells $\left(2.4 \times 10^{4}\right)$ were exposed to EGF $(10$ $\mathrm{ng} / \mathrm{mL})$ and treated with $\mathrm{FeF}(0-400 \mu \mathrm{g} / \mathrm{mL})$ in $1 \mathrm{~mL}$ of $0.3 \%$ Basal Medium Eagle (BME) agar containing 10\% FBS, $2 \mathrm{mM}$ L-glutamine, and $25 \mu \mathrm{g} / \mathrm{mL}$ gentamicin. The cultures were maintained at $37^{\circ} \mathrm{C}$, in a $5 \% \mathrm{CO}_{2}$ incubator for 14 days, and the cell's colonies were scored using a microscope «Motic AE 20» (China) and the Motic Image Plus computer program.

To estimate the effect of FeF on colony formation, HCT 116 , HT-29 or WiDR $\left(2.4 \times 10^{4}\right)$ were treated with $\mathrm{FeF}(0-400 \mu \mathrm{g} / \mathrm{mL})$ in $1 \mathrm{~mL}$ of $0.3 \%$ Basal Medium Eagle (BME) agar containing 10\% FBS, 2 mM L-glutamine, and $25 \mu \mathrm{g} / \mathrm{mL}$ gentamicin. The cultures were maintained in a $37^{\circ} \mathrm{C}, 5 \% \mathrm{CO}_{2}$ incubator for 14 days, and the cell colonies were scored as described above.

\section{Western blotting}

After cells $\left(6 \times 10^{5}\right)$ were cultured in a $10-\mathrm{cm}$ dish overnight, they were treated with FeF $(0-400 \mu \mathrm{g} /$ $\mathrm{mL}$ ) for $48 \mathrm{~h}$. Then the cells were starved in serum-free medium for another $12 \mathrm{~h}$ and treated with EGF (10 ng/ $\mathrm{mL}$ ) for $15 \mathrm{~min}$. The harvested cells were lysed with lysis buffer (50 mM Tris (pH 7.4), $150 \mathrm{mM} \mathrm{NaCl}, 1 \mathrm{mM}$ EDTA, $1 \mathrm{mM}$ EGTA, $10 \mathrm{mg} / \mathrm{mL}$ aprotinin, $10 \mathrm{mg} / \mathrm{mL}$ leupeptin, $5 \mathrm{mM}$ phenylmethanesulfonyluoride (PMSF), $1 \mathrm{mM}$ dithiolthreitol (DTT) containing 1\% Triton X-100). Insoluble debris was removed by centrifugation at 12000 rpm for $15 \mathrm{~min}$, and protein's content was determined using Bradford reagent "Bio-Rad" (Hercules, California, USA). Lysate protein $(20-40 \mu \mathrm{g})$ was subjected to $10 \%$ sodium-dodecyl sulfate-polyacrylamide gel (SDS PAG) and electrophoretically transferred to polyvinylidene difluoride membranes (PVDF) "Millipore" (Billerica, MA, USA). The membranes were blocked with $5 \%$ non-fat milk for $1 \mathrm{~h}$ and then incubated with the respective specific primary antibody at $4{ }^{\circ} \mathrm{C}$ overnight. Protein bands were visualized using an enhanced chemiluminescence reagent (ECL Plus) after hybridization with a HRP conjugated secondary antibody. Band density was quantified using the ImageJ software program (NIH).

\section{In vitro kinase assay}

Inactive ERK2 proteins $(1 \mu \mathrm{g})$ were used as the substrate for an in vitro kinase assay with $1.5 \mu \mathrm{g}$ of active TOPK. Firstly, active TOPK was incubated with FeF (200 and $400 \mu \mathrm{g} / \mathrm{mL}$ ) in $1 \times$ kinase buffer (25 mM Tris (pH 7.5), $5 \mathrm{mM}$ b-glycerophosphate, $2 \mathrm{mM}$ dithiothreitol (DTT), $0.1 \mathrm{mM} \mathrm{Na}_{3} \mathrm{VO}_{4}, 10 \mathrm{mM} \mathrm{MgCl}$, and $5 \mathrm{mM} \mathrm{MnCl}_{2}$ ) at $32^{\circ} \mathrm{C}$ for $15 \mathrm{~min}$. Then inactive ERK2 and $100 \mathrm{mM}$ ATP were added to reaction and incubated at $32^{\circ} \mathrm{C}$ for $1.5 \mathrm{~h}$. Reactions were stopped by adding $5 \times$ SDS sample buffer and then were analyzed by Western blotting. Band density was determined by GS-800 Calibrated Densitometer and quantified using "Quantity One 1-D analysis" software ("Bio Rad", USA). The percentage of inhibition of kinase activity by $\mathrm{FeF}$ was calculated compared with control (sample with TOPK active and ERK2 inactive).

\section{Preparation of water-insoluble fucoidan (IFeF)}

FeF $\left(1 \mathrm{~mL}, 10 \%\right.$, w/v) was mixed with $\mathrm{BaCl}_{2}$ $(1 \mathrm{~mL}, 10 \%, \mathrm{w} / \mathrm{v})$ and incubated overnight at $4^{\circ} \mathrm{C}$. The pellet was washed three times with $96 \%$ ethanol. The precipitated insoluble fucoidan (IFeF) was dried at room temperature [41].

\section{In vitro and ex vivo IFeF pull-down assays}

Human TOPK $(1 \mu \mathrm{g})$ was incubated with IFeF pellet $(1 \mathrm{mg})$ (or $\mathrm{BaSO}_{4}$ alone as a control) in $1 \times$ reaction buffer (50 mM Tris (pH 7.5), $5 \mathrm{mM}$ EDTA, $150 \mathrm{mM} \mathrm{NaCl}, 1 \mathrm{mM}$ DTT, $0,01 \%$ NP40, $2 \mathrm{mg} / \mathrm{mL}$ bovine serum albumin, 0.02 $\mathrm{mM}$ phenylmethylsulfonyl fluoride, $1 \times$ protease inhibitors) with gentle rocking overnight at $4{ }^{\circ} \mathrm{C}$. The samples were washed five times with washing buffer $(50 \mathrm{mM}$ Tris $(\mathrm{pH}$ 7.5), $5 \mathrm{mM}$ EDTA, $150 \mathrm{mM} \mathrm{NaCl}, 1 \mathrm{mM}$ DTT, $0.01 \%$ NP40, $0.02 \mathrm{mM}$ phenylmethylsulfonyl fluoride) and TOPK bound to IFeF was analyzed by Western Blotting 
with the primary antibody against human TOPK. For the ex vivo pull-down assay, HCT 116 cell lysate $(500 \mu \mathrm{g})$ were incubated with IFeF (1 mg) (or $\mathrm{BaSO}_{4}$ alone as a control) in $1 \times$ reaction buffer. After incubation with gentle rocking overnight at $4^{\circ} \mathrm{C}$, the pellet was washed 5 times with washing buffer and proteins bound to IFeF was analyzed by Western Blotting as previously described.

\section{Bacterial expression and purification of pET46-TOPK (His-TOPK)}

The topk gene was amplified by PCR and then cloned into pET-46 using a pET-46 Ek/LIC kit (Novagen, USA). His-TOPK fusion protein was expressed in BL21 (DE3) bacteria (Novagen, USA). Bacteria was grown at $37^{\circ} \mathrm{C}$ to an absorbance of $0.9-1.0$ at $600 \mathrm{~nm}$ and induced with $0.5 \mathrm{mM}$ IPTG overnight at $15^{\circ} \mathrm{C}$ and harvested by centrifugation. Cell pellets were suspended in $50 \mathrm{mM}$ Tris (pH 8.0) lysis buffer containing $200 \mathrm{mM} \mathrm{NaCl}$ and $10 \mathrm{mM}$ imidazole. After sonication and centrifugation, the supernatant fraction was incubated with Ni-NTA-agarose beads "Qiagen" (Germany) overnight at $4^{\circ} \mathrm{C}$. Beads were washed with lysis buffer and PBS and used for binding assay as $50 \%$ slurry.

\section{In vitro pull-down assay}

FeF (1 mg/mL) was incubated with TOPK-NiNTA-agarose beads (or Ni-NTA-agarose beads alone as a control; $200 \mu \mathrm{L}, 50 \%$ slurry) in the reaction buffer $(50 \mathrm{mM}$ Tris (pH 7.5), 5 mM EDTA, $150 \mathrm{mM} \mathrm{NaCl}, 1 \mathrm{mM}$ DTT, $0.01 \%$ Nonidet P-40, $2 \mathrm{mg} / \mathrm{mL}$ bovine serum albumin, $0.02 \mathrm{mM}$ phenylmethylsulfonyl fluoride, and $1 \mathrm{mg} / \mathrm{mL}$ protease inhibitor mixture). After incubation with gentle rocking overnight at $4^{\circ} \mathrm{C}$, the beads were washed 5 times with washing buffer (50 mM Tris ( $\mathrm{pH} 7.5$ ), 5 mM EDTA, $150 \mathrm{mM} \mathrm{NaCl}, 1 \mathrm{mM}$ DTT, $0.01 \%$ Nonidet P-40, $2 \mathrm{mg} / \mathrm{mL}$ bovine serum albumin, $0.02 \mathrm{mM}$ phenylmethylsulfonyl fluoride).

The binding between the TOPK-Ni-NTA-agarose beads and $\mathrm{FeF}$ was examined by color reaction with toluidine blue stain. Firstly, FeF (control) and TOPK-NiNTA-agarose-FeF complex were applied to the agarose gel electrophoresis. The electrophoresis was carried out in Tris-borate buffer $\mathrm{pH} 8.3$ (0.09 M Tris, 0.4 $\mathrm{M} \mathrm{H}_{3} \mathrm{BO}_{3}, 0.01$ $\mathrm{M}$ EDTA) at $25 \mathrm{~mA}$ for $2 \mathrm{~h}$. The gel was stained with 0.025 $\%$ solution of toluidine blue in acetic acid. Band density was determined by GS-800 Calibrated Densitometer and quantified using "Quantity One 1-D analysis" software "Bio-Rad" (Hercules, California, USA).

\section{Xenograft mouse model}

Athymic nude mice [6- to 9-week old] were obtained from Beijing HFK Bioscience CO., LTD (Beijing, China) and maintained under 'specific pathogen-free' conditions based on the guidelines established by the Laboratory of
Animal Center of the Fourth Military Medical University. Mice were divided into different groups $(n=6$ of each group). HCT 116 colon cancer cells $\left(3 \times 10^{6} / 0.1 \mathrm{ml}\right.$ $1 \times$ PBS) were injected subcutaneously into the right flank of each mouse. FeF $(1,10$, and $50 \mathrm{mg} / \mathrm{kg}$ of body weight) or vehicle was administered by oral injection three times a week for 20 days. Tumor volumes and body weights were measured every other day. The volume (V) of the tumor was calculated using the formula: volume $(\mathrm{v})=0.52($ length $(\mathrm{l}) \times$ width $(\mathrm{w}) \times$ height $(\mathrm{h}))$. Treated or non-treated groups of mice were euthanized and tumors extracted. Colon cancer tissue slides were prepared with paraffin sections after fixation with formalin and then stained with hematoxylin and eosin (H\&E) staining or p-ERK1/2 (Tyr202/Tyr204) and p-histone H3 (Ser10).

\section{Statistical analysis}

All assays were performed at least in triplicate. The results are expressed as the mean \pm standard deviation (SD). A Student's t-test was used to evaluate the data with the following significance levels: $* p<0.05, * * p<0.01$, $* * * p<0.001$.

\section{ACKNOWLEDGMENTS}

Dr. Ian McLeod critically read the manuscript.

\section{CONFLICTS OF INTEREST}

The authors declare no conflicts of interest.

\section{GRANT SUPPORT}

This project was supported by grants from the Independent innovation project of Huazhong University of Science and Technology (No.2014TS063\&2014ZZGH013) and the national Natural Science Foundation of China (No.81472602, 81450110449, 81570180, 81572529 $\&$ 30271302), and the major program of international cooperation of the Ministry of Science and Technology of People's Republic of China (No.2011DFA33110), and grant of Russian Foundation for Basic Research (RFBR) (No. 16-54-540004).

\section{REFERENCES}

1. Bode AM, Dong Z. Cancer prevention by food factors through targeting signal transduction pathways. Nutrition. 2004; 20: 89-94.

2. Laurienzo P. Marine polysaccharides in pharmaceutical applications: an overview. Mar Drugs. 2010; 8: 2435-2465.

3. Wijesekara I, Pangestuti R, Kim S. Biological activities and potential health benefits of sulfated polysaccharides derived from marine algae. Carbohydr Polym. 2011; 84: 14-21. 
4. Jiao G, Yu G, Zhang J, Ewart HS. Chemical structures and bioactivities of sulfated polysaccharides from marine algae. Mar Drugs. 2011; 9: 196-223.

5. Park HS, Kim GY, Nam TJ, Kim ND, Choi YH. Antiproliferative activity of fucoidan was associated with the induction of apoptosis and autophagy in AGS human gastric cancer cells. J Food Sci. 2011; 76: T77-83.

6. Foley SA, Mulloy B, Tuohy MG. An unfractionated fucoidan from Ascophyllum nodosum: extraction, characterization, and apoptotic effects in vitro. J Nat Prod. 2011; 74: 1851-1861.

7. Ale MT, Maruyama H, Tamauchi H, Mikkelsen JD, Meyer AS. Fucoidan from Sargassum sp. and Fucus vesiculosus reduces cell viability of lung carcinoma and melanoma cells in vitro and activates natural killer cells in mice in vivo. Int J Biol Macromol. 2011; 49: 331-336.

8. Synytsya A, Kim WJ, Kim SM, Pohl R, Synytsya A, Kvasnicka F, Copikova J, Park YI. Structure and antitumour activity of fucoidan isolated from sporophyll of Korean brown seaweed Undaria pinnatifida. Carbohydr Polym. 2010; 81: 41-48.

9. Zhang Z, Teruya K, Eto H, Shirahata S. Fucoidan extract induces apoptosis in MCF-7 cells via a mechanism involving the ROS-dependent JNK activation and mitochondriamediated pathways. PLoS One. 2011; 6: 27441-27455.

10. Kim EJ, Park SY, Lee JY, Park JH. Fucoidan present in brown algae induces apoptosis of human colon cancer cells. BMC Gastroenterol. 2010; 10: 96-107.

11. Hyun JH, Kim SC, Kang JI, Kim MK, Boo HJ, Kwon JM, Koh YS, Hyun JW, Park DB, Yoo ES, Kang HK. Apoptosis inducing activity of fucoidan in HCT-15 colon carcinoma cells. Biol Pharm Bull. 2009; 32: 1760-1764.

12. Yamasaki-Miyamoto $\mathrm{Y}$, Yamasaki M, Tachibana H, Yamada K. Fucoidan induces apoptosis through activation of caspase- 8 on human breast cancer MCF-7 cells. J Agric Food Chem. 2009; 57: 8677-8682.

13. Jin JO, Song MG, Kim YN, Park JI, Kwak JY. The mechanism of fucoidan-induced apoptosis in leukemic cells: involvement of ERK1/2, JNK, glutathione, and nitric oxide. Mol Carcinog. 2010; 49: 771-782.

14. Aisa Y, Miyakawa Y, Nakazato T, Shibata H, Saito K, Ikeda Y, Kizaki M. Fucoidan induces apoptosis of human HS-sultan cells accompanied by activation of caspase- 3 and down-regulation of ERK pathways. Am J Hematol. 2005; 78: 7-14.

15. Narazaki M, Segarra M, Tosato G. Sulfated polysaccharides identified as inducers of neuropilin-1 internalization and functional inhibition of VEGF165 and semaphorin3A. Blood. 2008; 111: 4126-4136.

16. Hu Y, Cheng SC, Chan KT, Ke Y, Xue B, Sin FW, Zeng C, Xie Y. Fucoidin enhances dendritic cell-mediated T-cell cytotoxicity against NY-ESO-1 expressing human cancer cells. Biochem Biophys Res Commun. 2010; 392: 329-334.
17. Lee H, Kim JS, Kim E. Fucoidan from seaweed Fucus vesiculosus inhibits migration and invasion of human lung cancer cell via PI3K-Akt-mTOR pathways. PLoS One. 2012; 7: e50624-e50634.

18. Ye J, Li Y, Teruya K, Katakura Y, Ichikawa A, Eto H, Hosoi M, Hosoi M, Nishimoto S, Shirahata S. Enzymedigested fucoidan extracts derived from seaweed Mozuku of Cladosiphon novae-caledoniae kylin inhibit invasion and angiogenesis of tumor cells. Cytotechnology. 2005; 47 : 117-126.

19. Dhillon AS, Hagan S, Rath O, Kolch W. MAP kinase signalling pathways in cancer. Oncogene. 2007; 26: 3279-3290.

20. Zhu F, Zykova TA, Kang BS, Wang Z, Ebeling MC, Abe Y, Ma WY, Bode AM, Dong Z. Bidirectional signals transduced by TOPK-ERK interaction increase tumorigenesis of HCT116 colorectal cancer cells. Gastroenterology. 2007; 133: 219-231.

21. Abe Y, Matsumoto S, Kito K, Ueda N. Cloning and expression of a novel MAPKK-like protein kinase, lymphokineactivated killer T-cell-originated protein kinase, specifically expressed in the testis and activated lymphoid cells. J Biol Chem. 2000; 275: 21525-21531.

22. He F, Yan Q, Fan L, Liu Y, Cui J, Wang J, Wang L, Wang Y, Wang Z, Guo Y, Huang G. PBK/TOPK in the differential diagnosis of cholangiocarcinoma from hepatocellular carcinoma and its involvement in prognosis of human cholangiocarcinoma. Hum Pathol. 2010; 41: 415-424.

23. Park JH, Nishidate T, Nakamura Y, Katagiri T. Critical roles of T-LAK cell-originated protein kinase in cytokinesis. Cancer Sci. 2010; 101: 403-411.

24. Simons-Evelyn M, Bailey-Dell K, Toretsky JA, Ross DD, Fenton R, Kalvakolanu D, Rapoport AP. PBK/TOPK is a novel mitotic kinase which is upregulated in Burkitt's lymphoma and other highly proliferative malignant cells. Blood Cells Mol Dis. 2001; 27: 825-829.

25. Oh SM, Zhu F, Cho YY, Lee KW, Kang BS, Kim HG, Zykova T, Bode AM, Dong Z. T-lymphokine-activated killer cell-originated protein kinase functions as a positive regulator of c-Jun-NH2-kinase 1 signaling and H-Ras-induced cell transformation. Cancer Res. 2007; 67: 5186-5194.

26. Barrett JC. Mechanisms of multistep carcinogenesis and carcinogen risk assessment. Environ Health Perspect. 1993; 100: 9-20.

27. Cerutti PA. Oxy-radicals and cancer. Lancet. 1994; 344: 862-863.

28. Colburn NH, Former BF, Nelson KA, Yuspa SH. Tumour promoter induces anchorage independence irreversibly. Nature. 1979; 281: 589-591.

29. Bode AM, Dong Z. Mitogen-activated protein kinase activation in UV-induced signal transduction. Sci STKE. 2003; 2003: RE2. 
30. Cowley S, Paterson H, Kemp P, Marshall CJ. Activation of MAP kinase kinase is necessary and sufficient for PC12 differentiation and for transformation of NIH $3 \mathrm{~T} 3$ cells. Cell. 1994; 77: 841-852.

31. Zvyagintseva TN, Shevchenko NM, Nazarenko EL, Gorbach VI, Urvantseva AM, Kiseleva MI, Isakov VV. Water-soluble polysaccharides of some far-eastern brown seaweeds. Distribution, structure, and their dependence on the developmental conditions. J Exp Mar Biol Ecol. 2003; 294: 1-13.

32. Li B, Lu F, Wei X, Zhao R. Fucoidan: structure and bioactivity. Molecules. 2008; 13: 1671-1695.

33. Rioux LE, Turgeon SL, Beaulieu M. Structural characterization of laminaran and galactofucan extracted from the brown seaweed Saccharina longicruris. Phytochemistry. 2010; 71: 1586-1595.

34. Skriptsova AV, Shevchenko NM, Zvyagintseva TN, Imbs TI. Monthly changes in the content composition of fucoidan from Undaria pinnatifida (Laminariales, Phaeophyta). J Appl Phycol. 2010; 22: 79-86.

35. Vishchuk OS, Ermakova SP, Zvyagintseva TN. The fucoidans from brown algae of Far-Eastern seas: anti-tumor activity and structure-function relationship. Food Chem. 2013; 141: 1211-1217.

36. Anastyuk SD, Shevchenko NM, Nazarenko EL, Dmitrenok PS, Zvyagintseva TN. Structural analysis of a fucoidan from the brown alga Fucus evanescens by MALDI-TOF and tandem ESI mass spectrometry. Carbohydr Res. 2009; 344: 779-787.

37. Ayllon V, O'Connor R. PBK/TOPK promotes tumour cell proliferation through $\mathrm{p} 38$ MAPK activity and regulation of the DNA damage response. Oncogene. 2007; 26: 3451-3461.

38. Hu F, Gartenhaus RB, Eichberg D, Liu Z, Fang HB, Rapoport AP. PBK/TOPK interacts with the DBD domain of tumor suppressor p53 and modulates expression of transcriptional targets including p21. Oncogene. 2010; 29: 5464-5474.

39. Zykova TA, Zhu F, Lu C, Higgins L, Tatsumi Y, Abe Y, Bode AM, Dong Z. Lymphokine-activated killer T-celloriginated protein kinase phosphorylation of histone H2AX prevents arsenite-induced apoptosis in RPMI7951 melanoma cells. Clin Cancer Res. 2006; 12: 6884-6893.

40. Lee NY, Ermakova SP, Zvyagintseva TN, Kang KW, Dong Z, Choi HS. Inhibitory effects of fucoidan on activation of epidermal growth factor receptor and cell transformation in JB6 Cl41 cells. Food Chem Toxicol. 2008; 46: 1793-800.

41. Lee NY, Ermakova SP, Choi HK, Kusaykin MI, Shevchenko NM, Zvyagintseva TN, Choi HS. Fucoidan from Laminaria cichorioides inhibits AP-1 transactivation and cell transformation in the mouse epidermal JB6 cells. Mol Carcinog. 2008; 47: 629-637.

42. Kim DJ, Li Y, Reddy K, Lee MH, Kim MO, Cho YY, Lee SY, Kim JE, Bode AM, Dong Z. Novel TOPK inhibitor HI-TOPK-032 effectively suppresses colon cancer growth. Cancer Res. 2012; 72: 3060-3068.

43. Shevchenko NM, Imbs TI, Urvantseva AI, Kusaykin MI, Kornienko VG, Zvyagintseva TN, Elyakova LA. Method of processing seaweed. Patent WO 2005/014657 2005. 